\title{
Challenges encountered during acid resin transfer preparation of fossil fish from Monte Bolca, Italy
}

\author{
Mark Graham and Lu Allington-Jones
}

\begin{abstract}
Five specimens of fossil fish from the Eocene deposits of Monte Bolca, Italy, were selected for preparation by the resin transfer method. The specimens were set in a synthetic resin, leaving the base exposed, and acetic acid was utilised to remove calcareous matrix from the exposed side. The specimens, of diverse genera, were obtained from various collectors from 1847 to 1933 and were therefore of both historical and scientific interest. The matrix blocks containing each fish were known to have been originally adhered onto supporting slabs of the same matrix with an unknown resin, and the joins concealed with a mortar. This paper records successful outcomes, and documents various challenges encountered during the preparation process, together with an account of the materials and techniques utilised. Due to the poor performance of the embedding resin initially chosen, a brief overview of resin types and trials of some of the commercially available alternatives is included.
\end{abstract}

Mark Graham, The Conservation Centre, The Natural History Museum, London, SW7 5BD, United Kingdom,m.graham@nhm.ac.uk

Lu Allington-Jones, The Conservation Centre, The Natural History Museum, London, SW7 5BD, United

Kingdom, I.allington-jones@nhm.ac.uk

Keywords: Acetic; acid; fossil; preparation; resin; deterioration

\section{INTRODUCTION}

The Monte Bolca outcrops near Verona, Italy, are limestone Lagerstätten containing extremely well-preserved fossil fish of Eocene age. The beds are thought to represent the earliest record of a perciform-dominated coral reef (Bellwood, 1996). The area was discovered in the sixteenth century and has so far produced around 250 fish species along with crocodiles, snakes, invertebrates and plants. Due to their undisturbed but two-dimensional nature, the fossil fish are ideal for prepara- tion by the resin transfer technique. The transfer of fossils was first documented at the end of the nineteenth century (Young, 1877; Holm 1890), and the use of acid was first documented by Bather (1908). Acids became widely used from the late 1930s and, following collaboration with zoological colleagues who had been embedding anatomical specimens in resins, Toombs and Rixon (1950) were the first to set specimens into a clear resin, to enable viewing from both sides. Whybrow (1985) and Lindsay $(1986,1995)$ provide reviews of the

PE Article Number: 18.2.4T

Copyright: Palaeontological Association May 2015

Submission: 16 February 2015. Acceptance: 27 April 2015

Graham, Mark and Allington-Jones, Lu 2015. Challenges encountered during acid resin transfer preparation of fossil fish from Monte Bolca, Italy. Palaeontologia Electronica 18.2.4T: 1-9

palaeo-electronica.org/content/2015/1190-challenges-monte-bolca-fish 
history and application of acid preparation, whilst Rutzky et al. (1994) provide a detailed guide to the various techniques.

The collections at the Natural History Museum, London, UK (NHM), contain several specimens prepared by the resin transfer technique. These have been created over several decades and with varying success. This article outlines the issues encountered during the application of this technique on five fish from Monte Bolca, requested for research. It also includes a comparison of a selection of resins, which are currently commercially available.

\section{THE SPECIMENS}

The blocks containing the specimens had been split laterally and the fossil fish were thus exposed in a single plane. The specimens prepared were: NHMUK (The Natural History Museum, United Kingdom) PV OR19011 Ductor leptosomus (purchased 1844); NHMUK PV OR21389 Sphyraena bolcensis (purchased 1847); NHMUK PV P1990 Vomeropsis longispinus (purchased 1882); NHMUK PV P9449 Seriola prisca (purchased, date unknown); NHMUK PV P16128 Lates gracilis (purchased 1931). In the case of specimen NHMUK PV P9449 both part and counterpart were held in the collection. The left lateral side was selected for preparation because more of the skull was contained within the matrix and thus offered greater morphological potential from exposure by chemical development.

The blocks all possessed cracks or had been reconstructed from the original broken sections of the same specimen, and had been embedded with unknown mortar and adhesive. Some areas had also suffered delamination and had been treated with a clear coating.

\section{FTIR (FOURIER-TRANSFORM INFRA-RED) SPECTROGRAPHIC ANALYSIS OF THE HISTORIC RESINS}

Resins and adhesives from the fish specimens were analysed using FTIR, as part of the condition reporting procedure. Samples of the adhesive from specimens NHMUK PV P1990 and NHMUK PV OR21389, and a mortar sample from NHMUK PV P16128 were crushed and incorporated into potassium bromide tablets. These were analysed using a Perkin Elmer Spectrum One FTIR Spectrometer and Spectrum software version 5.0.1. Spectra were compiled by averaging 32 scans and normalised against a potassium bro- mide background. The mortar displayed a profile between 3500 and $1500 \mathrm{~cm}^{-1}$ which is characteristic of phenolic resin (Koenig, 1999). This is supported by the C-O ester peak at $1081 \mathrm{~cm}-1$. This phenolic resin, likely to be Bakelite (Ventikou, 1999), was bulked out with calcium carbonate (as seen in the 1427,874 and $712 \mathrm{~cm}^{-1}$ peaks), which is likely to be ground from the bulk matrix surrounding the fossil. The adhesives were both found to be polyvinyl alcohol (Koenig, 1999), again bulked with calcium carbonate. The extra peak at $2514 \mathrm{~cm}^{-1}$ in $\mathrm{P} 1990$ is due to the presence of magnesium, implying a dolomite matrix source. The spectra can be seen in Figure 1.

\section{ACID TRANSFER TREATMENT}

\section{Materials}

Synthetic resins are generally used in two to four different ways during acid transfer: the embedding medium, consolidant for exposed bones and also as barriers to acid erosion. The latter includes gap-fills (such as Synocryl 9122x mixed with glass microballoons) that prevent uncontrolled under-cutting. Maisey et al. (1991) used Glyptal (of unspecified formula) as a consolidant and barrier combined. However, this was considered unsuitable for the Monte Bolca specimens, since a rigid and more readily reversible coating was required. Rixon (1976) found poly (butyl methacrylate) to be far superior to "Glyptal" and also to poly (methyl methacrylate) for consolidation. Furthermore, Rutzky et al. (1994) found that Glyptal Clear 1276 discolours and deteriorates over time, after 10 years specimens required conservation treatment. Rutzky et al. (1994) recommend Paraloid B67 (a polyisobutyl methacrylate) and Paraloid B72 (an ethyl methacrylate-methyl acrylate copolymer) for use in formic acid, but trials at the NHM have found that, in acetic acid, this discolours and loses adhesion. Lindsay (1986) documents the use of cellulose nitrate, Alvar 1570 in amyl acetate, Butvar (poly (vinyl butryal)), Vinalak 5911 and polystyrene coatings, but warns that most of these are too brittle, too sticky or shrink on curing. He recommends Synocryl 9123s, a poly (butyl methacrylate). This was used successfully at the NHM until 2003, but its production ceased and trials of alternative resins were undertaken. During these trials Synocryl 9122x was found to be the most suitable barrier coating for fossils during acetic acid immersion (Schiele, 2008). This is a poly (butyl methacrylate) thermoplastic acrylic polymer in xylene manufactured by Cray Valley, formerly known as Bedacryl 


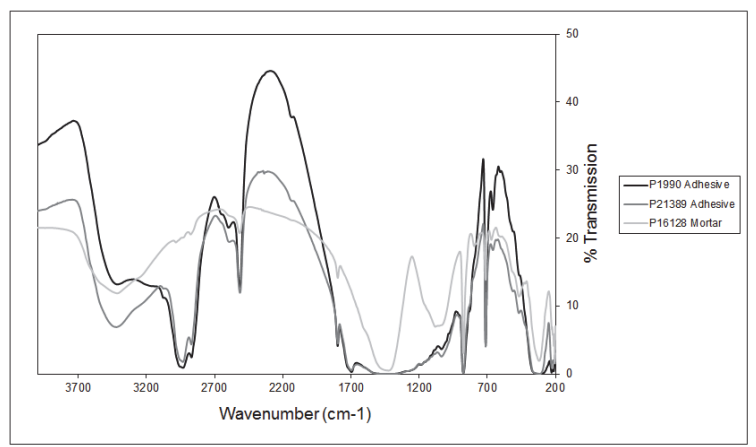

FIGURE 1. Fourier-Transform Infrared spectrograph of the three existing polymers. Wavenumber refers to the wavelength of light and \% Transmission refers to the amount of each wavelength that is transmitted through the sample. These are the parameters measured by the spectrometer to achieve an infra-red spectrum. Each peak is indicative of a different chemical bond and different substances will produce distinct patterns.

$122 \mathrm{x}$. It is heat resistant to $180^{\circ} \mathrm{C}$ and resistant to acetic acid, but easily removed with acetone. After several immersions the edges of the Synocryl $9122 x$ may begin to lift, whilst the matrix is removed, so in-painting with a fresh layer may be necessary to prevent undercuts. Microcrystalline wax has also been used as an effective barrier by the authors, but it is more suitable for use on areas of matrix rather than the specimen itself, since the high temperatures required to apply and remove it can be problematic.

Rutzky et al. (1994) describe several resin transfer techniques in great detail, they specify the use of Alplex Clear Casting Resin 132 (polyester resin in a styrene monomer) for embedding but with formic, not acetic, acid. Maisey et al. (1991) recommend Alpex (a cyclised rubber phenolic resin, not to be confused with Alplex Clear Casting 132) but find that etching of the cured resin occurs after prolonged exposure to acid. They suggest the incorporation of a transparent acrylic window to counteract this. Evander (1991) used an unspecified polyester resin whilst Rixon (1976) recommends polyester resins in general for embedding media and mentions Trylon EM301 in particular. This is no longer available, but Trylon offer two clear casting polyester resins EM310PA and EM400PA.

In the 1980s tests were undertaken at the $\mathrm{NHM}$ to discover the most suitable embedding medium. Epoxy resins, polyester resins and even a transparent silicon rubber were trialled. Scott Bader brand Strand Resin C was found to be the only viable option (Cornish, personal commun., 2014). Since then, Strand Resin C (polyester resin) has been used to embed transfer specimens at the $\mathrm{NHM}$, but this resin is no longer commercially available and an alternative had to be identified. In 2013, a two-part epoxy resin, Araldite 2020, was chosen because of its long-term chemical stability. This is an adhesive and laminating resin, which had been used successfully to manufacture clear mounts at the NHM and (according to the manufacturers' website) is also acid resistant. During acid immersion, however, this resin exhibited undesirable characteristics: a "tackiness" when set, which inclines it to mark easily; inconsistency of clarity (some areas remained transparent when set, some became opaque after acid immersion); overall yellowing after acid immersion; cracking/splintering; and warping during drying. The acid transfer treatment undertaken using Araldite 2020 is outlined below.

\section{Processes and Techniques Employed}

Acid preparation is considered a destructive process in accordance with the NHM policies and procedures. Permission for "destructive sampling" was therefore first obtained by the researchers from the museum authorities. Following NHM Conservation Centre best practice guidelines the specimens were then photographed and condition reports created for each one. A project review, including the impact on the specimens was also produced. Labels were removed using a poultice of methyl cellulose and acid free tissue, left for one hour and gently peeled away. The labels were then dried between sheets of silicone release paper, blotting paper and weighted glass plates, before storage in inert polyester sleeves. The cement/ mortar was mechanically removed from the edges of each block using a NSK Electer Emax, model NE129 rotary cutter fitted with an Edenta $2.2 \mathrm{~cm}$ diameter diamond cutting disk, operated at 15000 $\mathrm{rpm}$. The blocks were partially immersed in acetone baths to loosen the resin between the top and bottom layers. On specimens NHMUK PV OR21389, NHMUK PV P1990 and NHMUK PV P19011 the two layers were pried apart using a small pallet knife but on specimens NHMUK PV P9449 and NHMUK PV P16128 the bottom layer was removed by cutting squares with the rotary blade into the matrix and carefully chipping out each cube with a small cold-chisel. Cracks within each block were filled with an acid-resistant paste (Synocryl 9122x mixed with glass microballoons) to avoid uncontrolled acid erosion. The surfaces of 

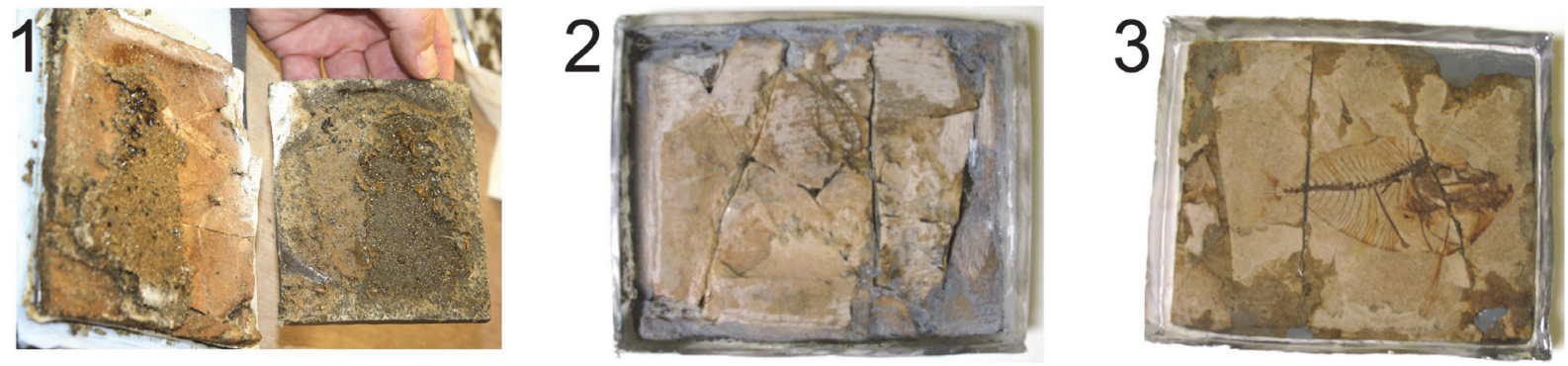

FIGURE 2. Specimen NHMUK PV P1990 during preparation. 1, the block split into halves, showing mortar. 2, The underside of the block set in resin, the majority of the matrix has been removed mechanically. 3, The top of the block, with the exposed fossil, embedded in resin.

the blocks were then cleaned using a Comco Accuflo micro abrasive blaster and 53 micron aluminium oxide powder, delivered at $40 \mathrm{psi}$ via a $0.76 \mathrm{~mm}$ diameter nozzle, and the edges of the fossils were defined using a pin vice so that the surface of the exposed bones would become as deeply inset into the resin as possible. Containers were manufactured from flat sided (corrugated interior) polypropylene board to hold the specimens and create the resin blocks, the two-part resin (Araldite 2020) was mixed, and a thin layer painted onto the fossil surface with a pure sable artists' brush to ensure that no bubbles were formed by trapped air. The remainder of the resin was then gently poured into the container and allowed to set for 48 hours. An acid immersion regime (described below) followed, consisting of acid immersion, removal of dissolved matrix with a soft brush and other mechanical means, rinsing, drying and the protective coating of exposed bone using Synocryl 9122x.

Figure 2 shows specimen NHMUK PV P1990 during the early stages of this process. Specimen NHMUK PV P16128 was contained within a darker matrix, possibly from a near-shore deposit, and contained a high clay content making it much less soluble in acid than the other blocks. Following poor results from acid immersion, this specimen was almost entirely mechanically prepared within the cured resin block.

\section{Record of Immersion, Rinsing and Drying Durations}

A mixture of $5 \%$ acetic acid and previously used (spent) acetic acid at $80 \%$ water $/ 20 \%$ preused solution was used for immersion, further buffered with 5 grams calcium orthophosphate per litre (Jeppsson et al., 1985; Jeppsson and Anehus, 1995). The $\mathrm{pH}$ level was maintained at 3.5 during immersions. The pre-used solution, referred to by Jeppsson et al. (1985) as "acetate soup", contains a concentration of calcium ions $\left(\mathrm{Ca}^{2+}\right)$ and reduces the destructive potential of acetic acid on the calcium phosphate fossils. The specimens underwent eight immersions of 24 hours, each followed by three days rinsing in gently running tap water (the jet directed away from the specimen, to prevent disturbing the bones) and a day air-drying at $19{ }^{\circ} \mathrm{C}$ (drying in an oven at higher temperatures was found to cause warping of the cured resin). The mechanical removal of non-carbonate residues from the bones was undertaken prior to drying. Additional resin was applied to freshly exposed bone following each drying and allowed to harden prior to photography and re-immersion in acid.

With the exception of NHMUK PV P16128 relatively little mechanical preparation in between acid immersions was necessary to the specimens and consisted of physical removal of residues from the exposed bones. Nevertheless, due to the very fragile nature of the small bones, this process was time-consuming and undertaken under the microscope. In addition, the original resin, which had been used to adhere the blocks and gap fill, required removal when it became exposed by the acid as it would otherwise protrude above the fossil-bearing surfaces. In the case of NHMUK PV P16128, careful removal of weakened matrix flakes, which were not fully dissolved by acid, was carried out with a scalpel and pin under the microscope following each immersion.

Following the eight full-block immersions, which removed most of the matrix from the specimens, smaller areas of undissolved matrix (mainly in the cranial areas) were removed by partialimmersion of the specimens in acid to minimise acid exposure on the rest of the skeletons.

To compensate for the etching and opacity of the Araldite 2020 following acid immersion, the cured resin surfaces were rubbed down with wet and dry fine abrasive paper, rinsed in water and 


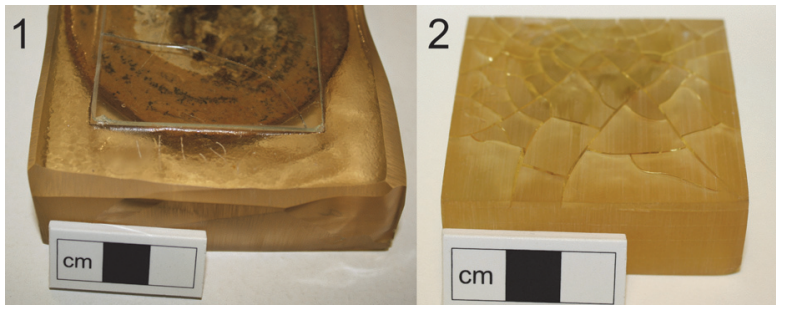

FIGURE 3. 1, Yellowed resin shows dimpled (etched) surface. A glass plate has been added to enhance clarity. 2, Yellowed resin displaying severe cracking and near opacity.

thoroughly dried and a second layer of the resin applied. This initially brought the surfaces to a clear finish, but these deteriorated again following subsequent immersions. Cracked and broken areas of Araldite 2020 surrounding specimens NHMUK PV P1990 and NHMUK OR21389 were removed and resin re-applied, but each fresh application subsequently failed. Fortunately, the areas affected were at a sufficient distance from the specimens that no damage occurred. The project was completed over a period of 20 weeks.

\section{Determining the Most Suitable Embedding Resin}

Following the poor performance of Araldite 2020, alternative resins were investigated. Traditionally "Strand Resin C" manufactured by Scott Bader Company (an isopthalic polyester) has been used at the NHM but this is no longer commercially available. It also suffers from yellowing, clouding and will crack if applied in an inappropriately thick layer (Figure 3). A replacement must perform as well, or better than Strand Resin C.

The choice of embedding media can be bewildering, because there are many commercially available synthetic resins. These can be grouped into types: phenolic, polyester, acrylic and epoxy resins. Phenolic resin is formed by the reaction of phenol and formaldehyde (Fibre Max Composites, 2013). It generally requires high curing temperatures and pressures so is not suitable for fossil transfer. The condensation reaction also produces volatile by-products (Cripps, 2014a).

There are two main types of polyester resin: orthophthalic and isophthalic, the latter is more expensive but generally possesses higher chemical resistance. Most polyester resins are a solution of polyester in a monomer such as styrene, which reduces viscosity and enables curing through cross-linking of the molecular chains of the polyester. A peroxide initiator and an accelerator catalyst are used to activate vinyl polymerisation, but con- siderable heat production and shrinkage can occur during this process (Horie, 1987; Cripps, 2014b). Vinylester resin is a bisphenol chlorinated polyester resin. It has higher mechanical strength and resistance to water than polyester resin but requires high curing temperatures (Fibre Max Composites, 2013) so would be unsuitable for embedding fossils.

Acrylic resins are thermoplastics derived from the polymersiation of acrylic or methacrylic acid. They have good resistance to oxidation and yellowing with age (Davison and Newton, 2003). Paraloid B72 is an acrylic resin, an ethyl methacrylate-methacrylate copolymer commonly used in conservation (Koob, 1986) and preparation (Davidson and Brown, 2012), but it has a relatively low glass transition temperature of $40^{\circ} \mathrm{C}$ and has been found to perform poorly in acetic acid immersion and drying cycles at the NHM.

Epoxy resins are cured by the addition of a hardener (usually an aliphatic amine or amide) rather than a catalyst (Horie, 1987). The hardener itself reacts with the resin and must therefore be mixed correctly (Cripps, 2014a). Epoxy resins are commonly prepared from a reaction of bis-phenol A and epichlorohydrin (Fibre Max Composites, 2013). They are generally more resistant to degradation than other resin types, possess good water resistance and low shrinkage during cure (Horie, 1987; Cripps, 2014a).

To assess currently available products and their suitability for use in acid preparation, a range of easy to use synthetic resins were investigated. Six resins (containing no fossil material) were subjected to five cycles of the same immersion regime as the fish specimens (24 hour immersions in 5\% acetic acid, buffered with calcium orthophosphate followed by three days of rinsing and then air drying). The resins were Isopthalic Polyester Resin and Special Water Clear Casting Resin (Synolite 0328-A-1 an orthopthalic resin), both by Fibreglass Direct; Clear Casting Resin (also an orthopthalic resin) by Tiranti, with and without $1 \%$ UV stabiliser additive; Araldite 2020 by Huntsman and Epotek301 by Epoxy Technology (both epoxies). These resins were chosen to represent a range of the types available on the market. Even though Araldite 2020 had performed poorly in real situations, it was included in the trials to provide a benchmark. The Isopthalic resin was tested at both $2 \%$ catalyst and at $1 \%$, the latter recommended by the manufacturer to reduce exothermal effect and produce a lighter colour. Within an extraction hood, each resin was mixed according to manufacturer's 
TABLE 1. Results of resin trials.

\begin{tabular}{|c|c|c|c|}
\hline Resin and layer thickness & $\begin{array}{l}\text { Excessive heat produced } \\
\text { during curing }\end{array}$ & $\begin{array}{l}\text { Colour when } \\
\text { cured }\end{array}$ & Appearance following acid treatments \\
\hline Epo-tek301, 5 mm & No & Colourless & $\begin{array}{l}\text { Became soft and yellowed slightly, edges } \\
\text { flaked away }\end{array}$ \\
\hline Epo-tek301, 10 mm & No & Colourless & $\begin{array}{l}\text { Became soft and yellowed slightly, edges } \\
\text { flaked away }\end{array}$ \\
\hline Tiranti Clear Casting, $5 \mathrm{~mm}$ & No & Colourless & Colourless, white bloom on surface. \\
\hline Tiranti Clear Casting, $10 \mathrm{~mm}$ & Yes & Colourless & Colourless, white bloom on surface. \\
\hline $\begin{array}{l}\text { Tiranti Clear Casting + UV stabiliser, } \\
5 \mathrm{~mm}\end{array}$ & Yes & Colourless & Colourless, white bloom on surface. \\
\hline $\begin{array}{l}\text { Tiranti Clear Casting + UV stabiliser, } \\
10 \mathrm{~mm}\end{array}$ & Yes & Colourless & Colourless, white bloom on surface. \\
\hline $\begin{array}{l}\text { Isopthalic Resin PA plus } 1 \% \\
\text { catalyst, } 5 \mathrm{~mm}\end{array}$ & Yes & Amber & Amber, severe white bloom on surface. \\
\hline $\begin{array}{l}\text { Isopthalic Resin PA plus 1\% } \\
\text { catalyst, } 5 \mathrm{~mm}\end{array}$ & Yes & Amber & Amber, severe white bloom on edges. \\
\hline $\begin{array}{l}\text { Isopthalic Resin PA plus } 2 \% \\
\text { catalyst, } 10 \mathrm{~mm}\end{array}$ & Yes & Dark Amber & Amber, slight white bloom on surface. \\
\hline $\begin{array}{l}\text { Isopthalic Resin PA plus } 2 \% \\
\text { catalyst, } 10 \mathrm{~mm}\end{array}$ & Yes & Dark Amber & Amber, severe white bloom on surface. \\
\hline Araldite $2020,5 \mathrm{~mm}$ & No & Colourless & $\begin{array}{l}\text { Moderate yellowing and severe } \\
\text { decomposition of form due to extreme } \\
\text { softening. Remained flexible after } \\
\text { treatment. }\end{array}$ \\
\hline Araldite $2020,10 \mathrm{~mm}$ & No & Colourless & $\begin{array}{l}\text { Moderate yellowing and severe } \\
\text { decomposition of form due to extreme } \\
\text { softening. Edges and flaked pieces are } \\
\text { flexible. }\end{array}$ \\
\hline Water White Clear Casting, $5 \mathrm{~mm}$ & No & Colourless & Clear, colourless. \\
\hline Water White Clear Casting, $10 \mathrm{~mm}$ & No & Colourless & Colourless, slightly frosted in places. \\
\hline
\end{tabular}

instructions and then poured into two shallow trays to set (personal protective equipment was worn according to the Material Safety Data Sheets for each set of chemicals). $10 \mathrm{ml}$ was poured into one tray, to produce a layer approximately $5 \mathrm{~mm}$ in thickness, whilst $40 \mathrm{ml}$ was poured into the second tray to produce a layer just over $10 \mathrm{~mm}$. The difference in thickness was tested because thick layers are more desirable for stability during treatment, but can undergo shrinkage cracking and produce higher temperatures during curing (Davison and Newton, 2003).

The ideal properties of an embedding resin would be long-term chemical stability, resistance to immersion in acetic acid, low volatile emission during curing, unreactive with the specimen or matrix, excellent optical clarity, low temperature generation during curing, and no shrinkage, cracking or warping during curing or throughout immersion cycles.

Table 1 shows the results of the resin trials. The Water White Clear Casting (Synolite 0328-A-
1) gave the best results for clarity, low heat generation, rigidity and structural integrity. Although the surface on some samples developed a slight frosting effect, this can be remedied by painting on a layer of the same resin after all cycles have been completed.

\section{CONCLUSIONS}

Insofar as historic specimens of fossil fish from the Monte Bolca location are concerned, where the fossil-bearing slab has been attached to a second, supporting slab of matrix, the preparator should anticipate a significant amount of mechanical preparation to be necessary (in order to reduce block depth) to augment the (traditionally) chemical-only acid-resin transfer technique. When removing old resin, such as the dark brown Bakelite encountered during this project, immersion in solvents should be avoided because the resultant contaminated fluid can stain the specimen and be difficult to remove. Furthermore, cured resins, 


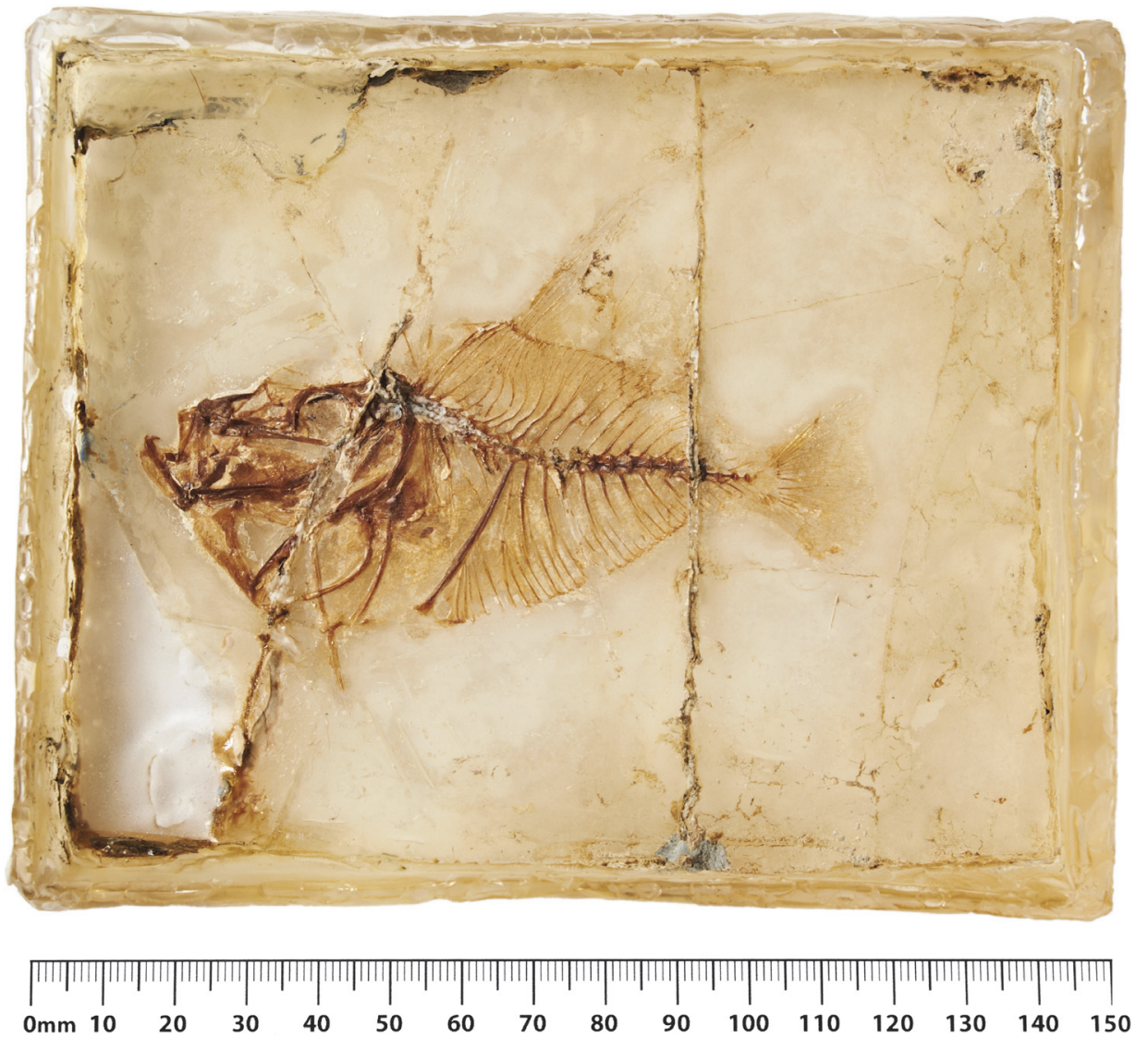

FIGURE 4. NHMUK PV P1990 after complete preparation.

when softened, can form a coating on rotary blades, effectively blunting the abrasive surfaces and cutting edges. Therefore careful prising apart of the blocks, where practicable, or cutting matrix into cubes, which can be levered off with a blunt blade is recommended.

The exposed bones were effectively protected during acid immersion by the addition of spent acetic acid and Calcium orthophosphate, which elevate the $\mathrm{Ca}^{2+}$ ion concentration in the solution. Following rinsing and drying, the bones were successfully protected by applying (with a small, soft brush) the acid-resistant resin Synocryl 9122x in $50 \%$ solution with acetone. Figure 4 shows the results upon completion of acid preparation of specimen NHMUK PV P1990. Araldite 2020 was, however, found to be unsuitable as an embedding resin and required several stages of restoration.

The initial failures and tests demonstrate that new resins must be trialled before application, regardless of manufacturer's claims, and that resins of similar types perform very differently. Not all polyesters, for example, cure at low enough temperatures or resist discolouration. Following these trials, Synolite 0328-A-1 was subsequently tested on real specimens and performed extremely well (Figure 5). Based upon the experience with these specimens, and the resin tests documented herein, the authors recommend that Synolite (a pre-accelerated, thixotropic, low styrene emission, orthophthalic based unsaturated polyester resin) such as Water White Clear Casting resin (Synolite 0328-A1) by Fibreglass Direct, be used when the transfer method of acid preparation is undertaken.

\section{FUTURE PROSPECTS}

A new protocol for the resin transfer method should be introduced. All new resins should be trialled before treatment commences and "blanks" of resin should be catalogued, dated and associated with the treatment records for the prepared specimens. 


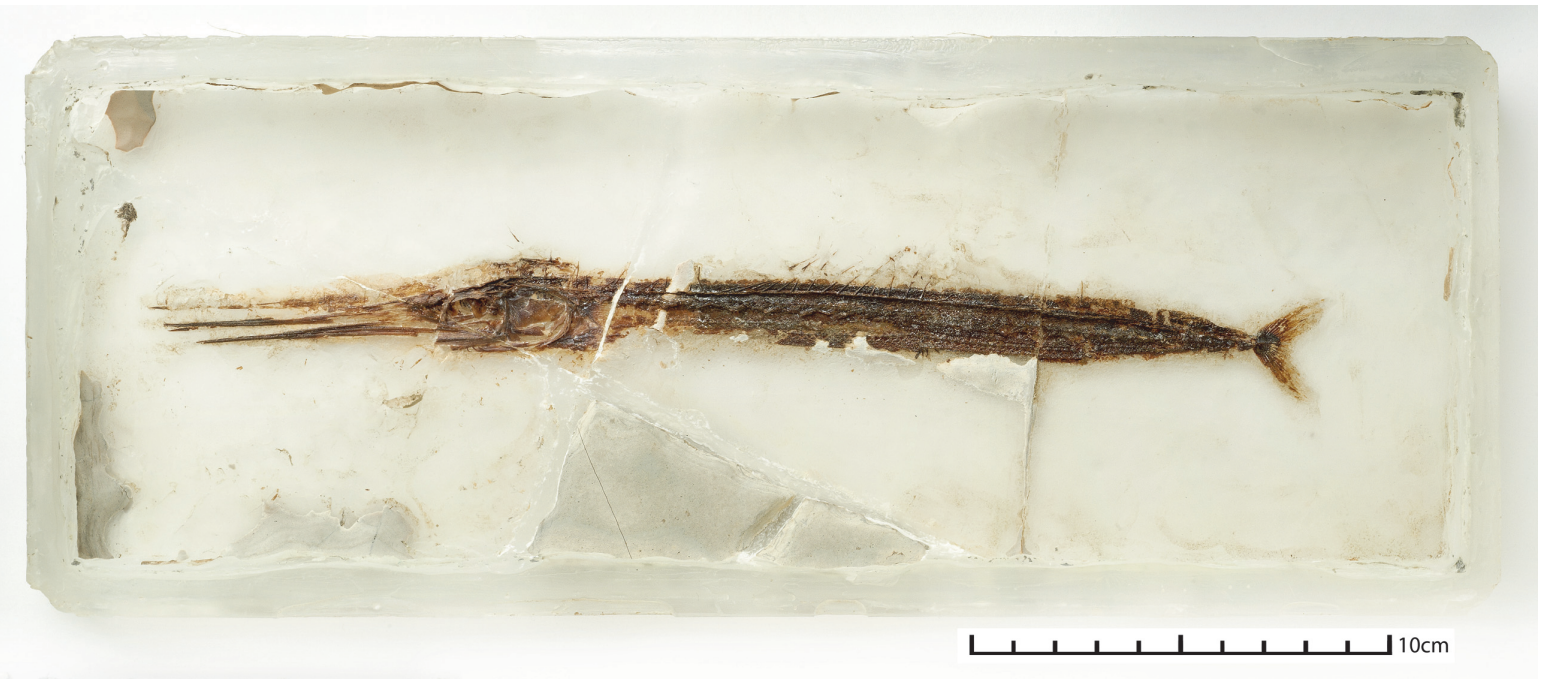

FIGURE 5. Oxford University Museum specimen CM4312 Blochius longirostris, set in Synolite 0328-A-1.

\section{ACKNOWLEDGEMENTS}

We thank M. Friedman, Oxford University Earth Sciences and Z. Johanson of the NHM for consultation during preparation of the specimens. We also thank C. Collins of the Conservation Centre (NHM) and the editor and reviewers for constructive suggestions for improvement of this manuscript.

\section{REFERENCES}

Bather, F.A. 1908. The preparation and preservation of fossils. Museums Journal, 8:76-90.

Bellwood, D.R. 1996. The Eocene fishes of Monte Bolca: the earliest coral reef fish assemblage. Coral Reefs, 15:11-19.

Cripps, D. 2014a. Epoxy resins, accessed 6 February 2014. www.netcomposites.com/guide/epoxy-resins/ 10.

Cripps, D. 2014b. Polyester resins, accessed 6 February 2014. www.netcomposites.com/guide/epoxy-resins/ 8.

Davidson, A. and Brown, G.W. 2012. ParaloidTM B-72: practical tips for the vertebrate fossil preparatory. Collection Forum, 26:99-119.

Davison, S. and Newton, R.G. 2003. Conservation and Restoration of Glass. 2nd edition. Butterworth-Heinemann, Oxford.

Evander, R.L. 1991. Standard preparation technique for fossil fish from the Romualdo Member of the Santana Formation, accessed 5 October 2013. www.preparation.paleo.amnh.org/assets/Evander-Romualdopreptechnique.pdf.

Fibre Max Composites. 2013. Types of resin families, accessed 6 February 2014. www.fibremaxcomposites.com/shop/index_files/resinsystems.html.
Holm, G. 1890. Gotlands graptoliter. Svenska Vetenskap-Akademie Handlingar, 16:1-34.

Horie, V. 1987. Materials for Conservation Organic Consolidants Adhesives and Coatings. Butterworths, London.

Jeppsson, L. and Anehus, R. 1995. A buffered formic acid transfer technique for conodont extraction. Journal of Paleontology, 69:790-794.

Jeppsson, L., Fredholm, D., and Mattiasson, B. 1985. Acetic acid and phosphatic fossils - a warning. Journal of Paleontology, 59:952-956.

Koenig, J.L. 1999. Spectroscopy of Polymers. 2nd Edition. Elsevier, Amsterdam.

Koob, S. 1986. The Use of Paraloid B-72 as an adhesive: Its application for archaeological ceramics and other materials. Studies in Conservation, 31:7-14.

Lindsay, W. 1986. The acid technique in vertebrate palaeontology: a review. Geological Curator, 4:455461.

Lindsay, W. 1995. A review of the acid technique, p. 95101. In Collins, C. (ed.), The Care and Conservation of Palaeontological Material. Butterworth-Heinemann, Oxford. Maisey, J.G., Rutzky, I., Blum, S., and Elvers, W. 1991. Laboratory preparation techniques, p. 99-105. In Maisey, J.G. (ed.), Santana Fossils an Illustrated Atlas. T.F.H. Publications, New York.

Rixon, A.E. 1976. Fossil Animal Remain their Preparation and Conservation. Athlone Press, London.

Rutzky, I., Elvers, W.B., Maisey, J.G., and Kellner, A.W.A. 1994. Chemical preparation techniques, p. 155-179. In Leiggi, P. and May, P. (eds.), Vertebrate Palaeontological Techniques Volume 1. Cambridge University Press, Cambridge.

Schiele, M. 2008. The effectiveness of Synocryl 9123s during the acid preparation process. Abstracts of the Symposium of Palaeontological Preparation and Conservation annual meeting, Tuesday, 2nd September, Geological Survey of Ireland, 10. 
Toombs, H. and Rixon, A.E. 1950. The use of plastics in the "transfer method" of preparing fossils. The Museums Journal, 50:105-107.

Ventikou, M. 1999. Old treatment, new problem: Bakelite as a consolidant. V\&A Conservation Journal, 32:5-7.
Whybrow, P.J. 1985. A history of fossil collecting and preparation techniques. Curator the Museum Journal, 28:5-26.

Young, J. 1877. Notes on a new method of fixing fronds of Carboniferous Polyzoa on a layer of asphalt to show the celluliferous face. Proceedings of the Natural History Society of Glasgow, 3:207-210. 